\title{
Rare Lipomatous Tumor of the Posterior Mediastinum in Children
}

\author{
Takahiro Homma $^{1}$ Yoshinori Doki ${ }^{2}$ Kazutaka Senda ${ }^{2}$ Masayoshi Toge ${ }^{2}$ Yutaka Yamamoto ${ }^{1}$ \\ Toshihiro Ojima $^{2}$ Yoshifumi Shimada ${ }^{2}$ Naoki Yoshimura ${ }^{2}$ \\ ${ }^{1}$ Division of Thoracic Surgery, Joestu General Hospital, Joetsu, Niigata, \\ Japan \\ 2 Department of General Thoracic and Cardiovascular Surgery, \\ University of Toyama, Toyama, Toyama, Japan \\ Address for correspondence Takahiro Homma, MD, Division of \\ Thoracic Surgery, Joetsu General Hospital, 148-1 Daido-Fukuda, Joetsu, \\ Niigata 943-8507, Japan (e-mail: hommat.tym@gmail.com).
}

Eur J Pediatr Surg Rep 2014;2:50-53.
Abstract
Keywords
- pediatric
- mediastinum
- tumor
- lipoma
- lipoblastoma

The mediastinum is a unique anatomic area containing various structures and pluripotent cells, which allow for the development of a range of tumors. We report two pediatric cases of a lipomatous tumor of the posterior mediastinum. Complete surgical excision of the mass in each was achieved through a lateral thoracotomy. Histopathologic findings showed a lipoma in one case and a lipoblastoma in the other. A lipomatous tumor in the posterior mediastinum is extremely rare and preoperative diagnosis is difficult. When an operative plan is being considered, the presence of a potentially malignant tumor should be kept in mind.

\section{Introduction}

Neurogenic tumors occur most frequently in the posterior mediastinum in all age groups. ${ }^{1}$ We report two cases of a rare lipomatous tumor of the posterior mediastinum in children. Lipomatous tumors may occur in any area of the body. ${ }^{2}$ Differential diagnosis of a lipomatous deep mass in a child can include lipoma, lipoblastoma, and liposarcoma. Lipomatous tumors located in the mediastinum are extremely rare, though more commonly found in the anterior as compared with the posterior mediastinum, ${ }^{1}$ and it has been speculated that they arise within adipose tissue of the thymus. Along with reports of these cases, we present some differences and similarities noted.

\section{Case}

\section{Patient 1}

A 4-year-old boy was presented with a persistent nocturnal cough and no inflammatory findings were noted in a clinical examination. A chest film showed a mass within the right hemithorax, while computed tomography (CT) and magnetic resonance imaging (MRI) of the chest revealed the giant lipomatous mass with a homogenous component occupying the right posterior mediastinum, with the heart and mediastinal structures shifted to the left ( - Fig. $1 \mathrm{a}-\mathrm{c}$ ). We performed a posterior thoracotomy, which showed that the mass was encapsulated, with no significant involvement of the surrounding tissues. A complete excision was performed and the postoperative course was uneventful. The histopathologic findings were consistent with a diagnosis of a lipoma composed of mature fat cells ( - Fig. 1d).

\section{Patient 2}

A 3-year-old girl was presented with a persistent nocturnal cough and no inflammatory findings were noted in a clinical examination. A chest film showed a left hilar mass, while CT and MRI of the chest revealed the giant lipomatous mass in the left posterior mediastinum near the vertebrae and ribs ( - Fig. $2 \mathrm{a}-\mathrm{c}$ ). The mass showed mixed tissue content with a nonadipose tissue component, with no calcification seen within the mass and no significant contrast enhancement observed. The patient underwent a posterior thoracotomy. The mass was encapsulated with the mediastinal pleura and no significant involvement with surrounding tissues was observed. A complete excision was performed including the received

August 6, 2013 accepted after revision

November 13, 2013

published online

February 10, 2014

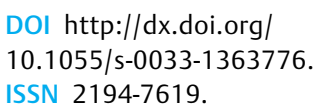

DOI http://dx.doi.org/ 10.1055/s-0033-1363776. ISSN 2194-7619.

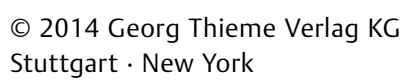

License terms

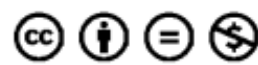




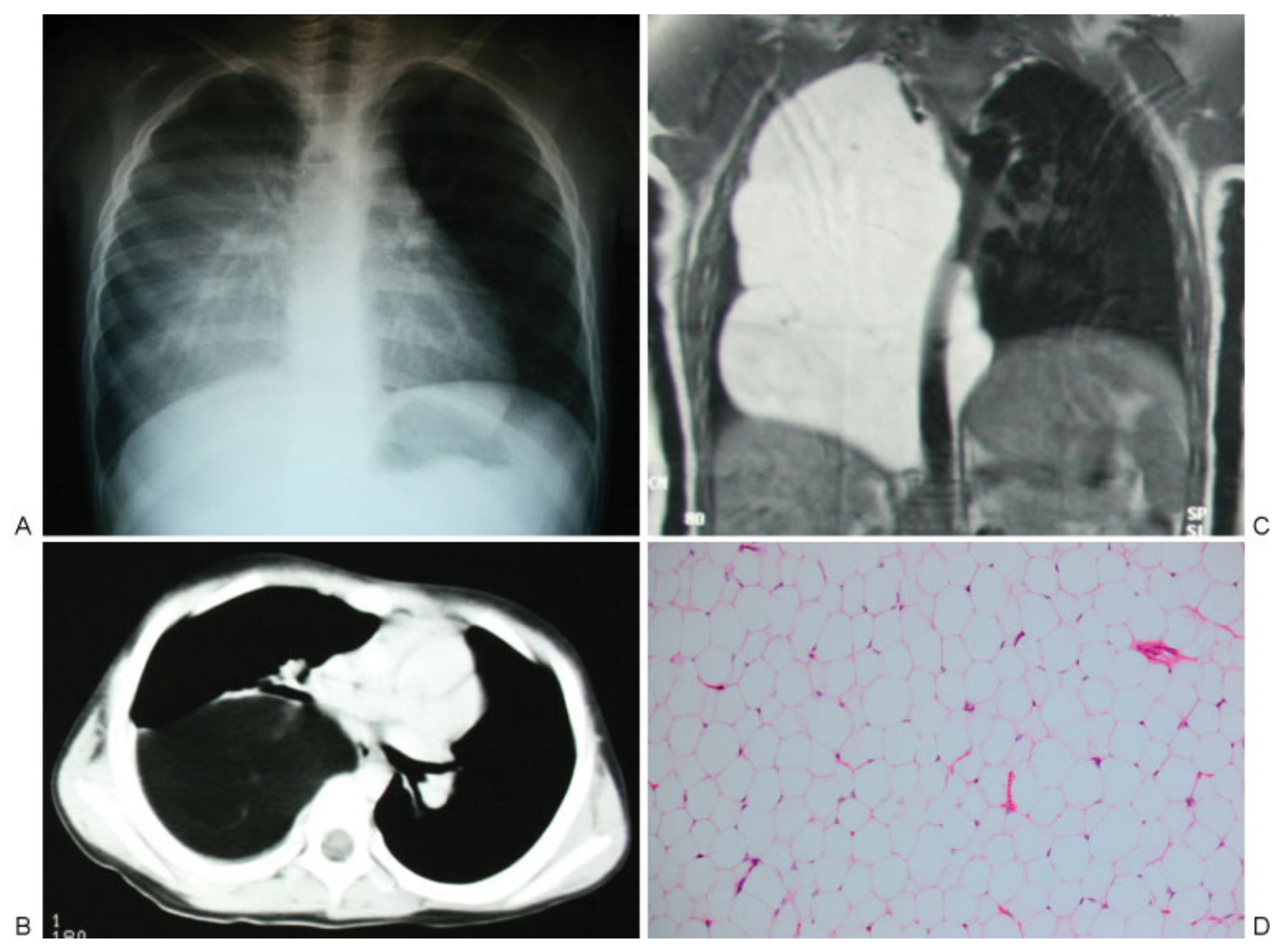

Fig. 1 (a) Chest film showing the mass within the right hemithorax. (b) Computed tomography showing the homogenous mass occupying the right posterior hemithorax, with the heart and mediastinal structures shifted to the left. (c) T1-weighted magnetic resonance imaging of the chest showing the homogenous mass of high intensity, which parallels signal intensity of subcutaneous fat. (d) Histologic view showing mature adipocytes (hematoxylin-eosin, original magnification $\times 20$ ).

mediastinal parietal pleura and the postoperative course was uneventful. The histopathologic findings were consistent with a diagnosis of a lipoblastoma composed of mature and immature fat cells with gelatinous nodules ( - Fig. $2 \mathrm{~d}$ ).

\section{Discussion}

Differential diagnosis of a lipomatous deep mass can include lipoma, lipoblastoma, and liposarcoma, ${ }^{2}$ which share three similarities among them. First, a tumor located in the mediastinum is extremely rare. Mediastinal liposarcomas have been estimated to account for only 1 to $2 \%$ of all liposarcomas. ${ }^{3}$ Second, they are typically painless, ${ }^{2}$ though symptoms vary depending on the site of the tumor. Third, surgical resection is the mainstay of curative treatment. On the contrary, there are five primary differences among these tumors ( - Table 1): (1) peak age at onset, (2) site of predilection except for the extremities, (3) increasing rate, (4) recurrence rate, and (5) prognosis. Lipomas, fairly uncommon during the first two decades of life, usually arise in the extremities and trunk, ${ }^{4}$ while lipoblastomas occur most frequently in male children younger than 3 years, with common locations reported to be the trunk, neck, and extremities. ${ }^{5,6} \mathrm{~A}$ liposarcoma is an extremely unusual tumor in pediatric patients, accounting for less than $3 \%$ of all pediatric sarcomas, and usually occurs in the retroperitoneum and extremities. ${ }^{7}$

The most important issue in clinical practice is to determine whether the tumor is a lipoma, because lipoblastoma and liposarcoma have been reported to show rapid growth, along with a high recurrence rate and poor prognosis. ${ }^{2,3,5-7}$ Lipoblastoma recurrence has been noted in 14 to $25 \%$ of reported cases, ${ }^{6}$ usually because of incomplete resection or diffuse disease. Most pediatric liposarcoma have a myxoid characteristic and prognosis for conventional myxoid liposarcomas is good as compared with other types. ${ }^{7}$ However, those showing any significant (more than 5\%) round cell component should continue to be regarded as a high-grade sarcoma regardless of age group.

The mass in both of the present cases was a giant lipomatous tumor wrapped in the mediastinal pleura. Intraoperative findings and appearance were not useful for determination of a lipoma.

CT scanning can often reveal the lipid nature of tumors, though those findings are not useful to distinguish between lipoma, lipoblastoma, and liposarcoma. ${ }^{2,6}$ Thus, MRI is a method of choice for preoperative diagnosis. ${ }^{8}$ Lipomas have a characteristic signal intensity pattern that parallels that of subcutaneous fat (high on T1-weighted MRI, intermediate on T2-weighted MRI, and loss of signal intensity on fat- 


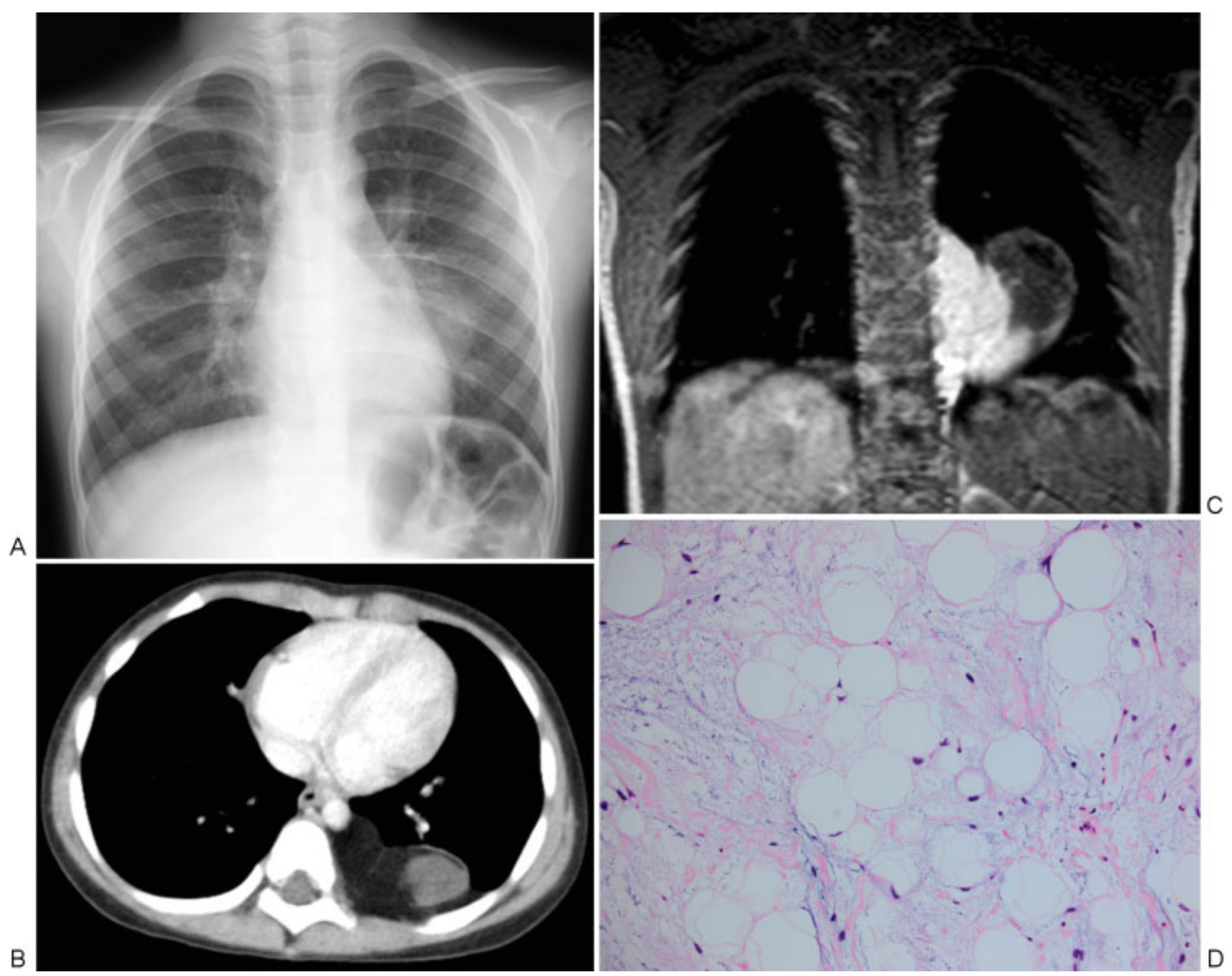

Fig. 2 (a) Chest film showing the left hilar mass. (b) Computed tomography showing the nonhomogenous mass in the left posterior mediastinum, with no contrast enhancement. (c) T1-weighted magnetic resonance imaging of the chest showing the mass near the vertebrae and ribs, with a signal intensity of nonadipose tissue component. (d) Histologic view showing mature and immature adipocytes (hematoxylin-eosin, original magnification $\times 20$ ).

Table 1 Characteristics of lipomatous tumors

\begin{tabular}{|c|c|c|c|}
\hline & Lipoma & Lipoblastoma & Liposarcoma \\
\hline Site of predilection & $\begin{array}{l}\text { Extremities } \\
\text { Trunk } \\
\text { Neck } \\
\text { Head }\end{array}$ & $\begin{array}{l}\text { Extremities } \\
\text { Trunk } \\
\text { Neck }\end{array}$ & $\begin{array}{l}\text { Extremities (mainly thigh) } \\
\text { retroperitoneum }\end{array}$ \\
\hline Peak age at onset & $\begin{array}{l}\text { Middle age } \\
\text { Rare in children }\end{array}$ & Children younger than 3 years & $\begin{array}{l}\text { Late middle age } \\
\text { Rare in children }\end{array}$ \\
\hline Tumor growth & Slow & Rapid & Rapid \\
\hline MRI & $\begin{array}{l}\text { Homogenous } \\
\text { High signal intensity on } \\
\text { T1-weighted images }\end{array}$ & $\begin{array}{l}\text { Heterogenous } \\
\text { Intermediate-to-high signal } \\
\text { intensity on T1-weighted images }\end{array}$ & $\begin{array}{l}\text { Thick septa } \\
\text { Absent lobulation } \\
\text { Pronounced enhancement } \\
\text { Globular and nodular enhancement }\end{array}$ \\
\hline Recurrence & $\begin{array}{l}\text { Rare } \\
\text { Malignant transformation } \\
\text { very rare }\end{array}$ & $\begin{array}{l}\text { Frequent (14-25\%) } \\
\text { Distant metastases not reported }\end{array}$ & Common (depends on histologic grade) \\
\hline Prognosis & Excellent & Good & Poor (depends on histologic grade) \\
\hline
\end{tabular}

Abbreviation: MRI, magnetic resonance imaging. 
suppressed MRI). In addition, a lipoblastoma can be heterogenous and shows intermediate-to-high signal intensity on T1weighted images according to the amount of immature lipoblasts present. On fat-suppressed MRI, lipoblastomas usually demonstrate areas of high-signal intensity, which can indicate their diagnosis. As for a liposarcoma, contrast-enhanced MRI can assist in detecting round cell components within the entire tumor, and aid in distinction between lowgrade and intermediated- or high-grade myxoid round cell liposarcomas. However, equivocal diagnosis can only be established with a histologic examination.

Tumor location is thought to be the most important prognostic factor, 2,3 principally because of resectability, which correlates with rate of recurrence. The prognosis for a mediastinal liposarcoma is poor because of late tumor detection, involvement of vital structures, and inability to achieve complete resection.

In our patients, though the masses originated in the posterior mediastinum, no significant involvement with surrounding tissues was observed and complete excision could be successfully completed.

Even if a liposarcoma of the mediastinum in child is suspected, surgical resection is primary curative treatment. Some adjuvant therapy and neoadjuvant therapy in patients with extremity soft tissue sarcoma have been described. They may also improve survival in patients with mediastinal liposarcoma. Radiotherapy plus surgery reported to be associated with high local control of myxoid liposarcoma radiation therapy associated with local control of soft-tissue sarcomas resected with positive margins. Adjuvant radiotherapy should be considered, because obtaining adequate margins of resection in mediastinum is difficult and most pediatric liposarcoma have a myxoid characteristic. ${ }^{2,7}$

Posttreatment surveillance via chest film and CT at every 6 months for first 2 years are recommended according to the low-grade liposarcoma, ${ }^{2}$ although the prognosis is good. Distant metastases have not been reported in lipoblastoma.

\section{Conclusion}

The posterior mediastinum is a rare site for a lipomatous tumor and preoperative diagnosis is difficult. As complete surgical resection is the best curative treatment and gives excellent results, the operative plan should be considered with the possibility of a malignant tumor in mind.

\section{Conflict of Interest}

None.

\section{References}

1 Macchiarini P, Ostertag H. Uncommon primary mediastinal tumours. Lancet Oncol 2004;5(2):107-118

2 Dalal KM, Antonescu CR, Singer S. Diagnosis and management of lipomatous tumors. J Surg Oncol 2008;97(4):298-313

3 Boland JM, Colby TV, Folpe AL. Liposarcomas of the mediastinum and thorax: a clinicopathologic and molecular cytogenetic study of 24 cases, emphasizing unusual and diverse histologic features. Am J Surg Pathol 2012;36(9):1395-1403

4 Salam GA. Lipoma excision. Am Fam Physician 2002;65(5): 901-904

5 Salem R, Zohd M, Njim L, et al. Lipoblastoma: a rare lesion in the differential diagnosis of childhood mediastinal tumors. J Pediatr Surg 2011;46(5):e21-e23

6 Moaath A, Raed E, Mohammad R, Mohammad S. Lipoblastoma: a rare mediastinal tumor. Ann Thorac Surg 2009;88(5):1695-1697

7 Alaggio R, Coffin CM, Weiss SW, et al. Liposarcomas in young patients: a study of 82 cases occurring in patients younger than 22 years of age. Am J Surg Pathol 2009;33(5):645-658

8 Castellote A, Vázquez E, Vera J, et al. Cervicothoracic lesions in infants and children. Radiographics 1999;19(3):583-600 